\title{
Social Media for Crisis Communication Management
}

\author{
Thouraya Snoussi ${ }^{1}$ \\ ${ }^{1}$ Associate Professor, College of Communication, University of Sharjah, UAE \\ *Correspondence: Thouraya Snoussi, tsnoussi@sharjah.ac.ae
}

\begin{abstract}
This paper analyzes trends related to the role of social media in crisis communication. The author posed a question about the attitudes of online media actors (communication, public relations and marketing experts) towards using social media as a strategic communication tool in times of crisis; Emphasis on two different crises: the 2016 Turkish political crisis and the global health pandemic (COVID-19) in 2020. Communications actors' perceptions and behaviors of social media in times of crisis were tracked through a mixed method (a content analysis of 40 online publications about the military coup attempt in Turkey, and $20 \mathrm{semi}$ structured in-depth interviews about the usage of social media during the quarantine period). The results showed that social media is a lifeboat that is provided to organizations in times of crisis, as communication with customers becomes a vital factor in managing critical situations. Meanwhile, some participants expressed reservations about confidence in the use of social media in times of crisis, stressing that these networks are a double-edged sword. As the keyword for crisis management, a strategic communication plan should take place via social media to discuss customer inquiries with clients, answer their questions, and try to reduce their anxiety, according to the interviewee.
\end{abstract}

Keywords: Social Media, Crisis communication, Management, Perceptions, Covid-19, Strategic communication plan

\section{ARTICLE INFORMATION}

Author(s): Thouraya Snoussi

Received: 15 Aug 2020; Accepted: 25 Aug, 2020; Article-in-press

e-ISSN: 2347-4696;

Paper Id: BMN-IJBMR-2020-4;

Citation: --

Webpage-link:

https://ijbmr.forexjournal.co.in/archive/volume-8/ijbmr-080302.html

\section{INTRODUCTION}

Smart digital communication applications have become a constant prerequisite for individuals and organizations. Its use varies according to the needs of users; stemming from the necessity of communication, the introduction of social media (SM) has reached the cultural, educational, marketing and political fields as an effective tool for strategic communication. Besides, social media, as an advanced platform, provides better communication in critical situations due to the opportunities it provides to exchange information quickly and effectively [1], which is the key to any successful administrative processes in dealing with an emergency; information, constantly flowing in social media, motivates its use to benefit emergency managers [2-4]. For this, social media can play a pivotal role during crises management in various fields $[5,6]$.

From small-scale disasters to global catastrophes in various fields such as economic, cultural, political, and health crises, social media is emerging as a growing force, valid as a strategic communication tool to limit losses and repercussions.
Over the past decade, SM has played an important role as a key driver supporting the path of some political events at times, and changing them at other times. The impact of modern digital communications applications in managing political crisis communications was indisputable during the socalled "Arab Spring" in 2011; Facebook has been ranked as an engine of change by a number of political experts and specialists in the field of media and communication. In July 2016, Face-Time was considered one of the factors that thwarted the military coup in Turkey, which gave a tremendous marketing breath to the iPhone company, which benefited commercially from the Turkish president's use of one of its applications during the period of the crisis that his country went through, in order to address his people at a critical time. This allows the author to question the true size of the role that social networks play in managing political crises.

This paper analyses the most prominent trends regarding the role of social media in crisis communication. To address the topic in an in-depth manner, the researcher will expose two types of them: An acute political crisis related to an attempted military coup in Turkey, and a global health crisis that we still suffer from: The Coronavirus pandemic; she chose to investigate in the first part, the trends of online media actors (online Journalists, communicators, and researchers), towards social media as a strategic communication tool in times of emergencies, through their online publications: A content analysis of a sample of articles circulated via the virtual space during the week following the attempted coup in Turkey (July $16-26,2016)$ was conducted to inspect the perceived role that 
Face-Time played during that crisis. In the second part, the main question is covered in a different approach; the author chose another crisis; it has chosen to tackle a severe and current global pandemic: Coronavirus, also called Covid-19, to investigate the way social media is viewed and used by communication, PR and marketing experts during the quarantine period via in depth, semi structured interviews.

\section{AIMS AND PURPOSES}

This study aims to emphasize the strategic role that social networks can play in communication during crises of all kinds, with a focus on national, political and global health crises. In addition, the researcher wants to measure the impact of social media on people in times of crisis and whether communication and marketing experts view it as a primary driver of change.

\section{SIGNIFICANCE}

The importance of this research lies in studying the evolution of social media usage in critical times mainly, in the fields of politics and health at the national and global levels. Tracking these uses from 2016 to 2020 may provide the author and reader with its real weight as a modern means of communication, and future trends for crisis management strategies using social networks.

\section{Literature review}

The term Crisis, defined as an event that "creates, sustains, or strengthens a cause" [7]; includes natural disasters, industrial accidents, and intentional events [8,9]; social media as a set of Internet-based applications based on ideological and technological foundations that allow the creation and exchange of user-generated content [10], can allow immediate response and interactive communication mainly during crises $[11,12]$.

In fact, several studies have considered the use of social media in many contexts; a number of researchers have supported integrating social networks as an educational tool, especially virtual classes that use Facebook and Instagram [13]; social networks appear to be considered a virtual open space for communication, interaction and influence using many tools such as blogs, instant messages and virtual communities in different contexts [6]. Jessica et al. [14] have focused on its use in medical field; they have explained that social media is a valuable means for professional physicians to enhance communication with surgeons and direct them to improve the interaction between doctors and patients as well as mentors and trainees. Though, some studies conducted in Bulgaria for example have shown the weak use of social media, where results showed no use for tools likes wikis [15]. Studies in the Arab region were focused on the incorporation of social media in the Emirati society; Al Jenaiby [16] noted that these networks are perceived as a vibrant source of information, vehicle of news, opinion sharing, cultural production and entertainment. Snoussi [6], stated three categories of social media uses by young people, as being considered as a source for exchanging academic materials, academic discussions and news spreading.

Most recent studies focused on the use of social media during the Covid-19 pandemic; Bernadetha [17] tested the effectiveness of distance learning using social media for Malaysian students during the quarantine period and noted that it is more suitable for theoretical courses.

In the field of integrated communications and marketing, many studies addressed the use of social media to approach customers. In fact, Lee, et al. [18] described the relationship between social media users and organizations as very complex; they noted that trust is the basis of all online communications. Luc, Stamp \& Antonoff [19] studied the range of users' perceptions of belief in social media and stressed the public's high prospects of integrity, empathy and goodwill in these networks. During crises, this relationship seems to be even more significant as the masses' use of social media increases (Pew Internet \& American Life, 2006); even journalists are increasingly using social media to generate news [20] due to their conviction that these networks can have a direct and indirect impact on audiences in times of emergency.

Literature review shows a particular focus on some specific domain of administration or management via social networks like public health, environmental disasters, or case studies related to a particular political events, etc. Horth et al. [21] discussed the role of social media in stimulating civic engagement and managing distress and grief, through a case study of participants living in Tokyo in the history of the terrible events surrounding the Japan earthquake and the tsunami of March 11, 2011.

Subba et al. [22] studied the crisis communication management of the National Police Headquarters via Social Media, during the 2015 Nepal earthquake; the authors pointed out that Twitter, as the most popular social networking site, has been used as an effective communication and cooperation platform between the public authority and the general public, which supported the establishment of a cooperative relationship with regard to the dissemination and exchange of information related to road conditions, casualties, landslides, relief and rescue operations, communications, and the disappearance of missing persons.

Power and Kibell [23] addressed the role of social media intelligence analyst as a new operational role within a State Control Center in Victoria, (Australia) dedicated to obtaining situational awareness from social networks to support emergency management decision-making. They also examined how the role fits within a command and control organization's structure during an emergency event.

Saroi and Pal examined the connection between emergencies and social media. The authors tracked the impact of emergencies incidence on virtual space, asking how social 
media is dealing with disaster news effectively and helping to create awareness; they also discussed the role that social media could play in helping governments manage emergencies and minimize harms.

To sum up, previous studies have mostly involved research on social media in many contexts; the primary concern has been to measure the impact of social networking integration in many areas and how it shapes the relationship with the target audience. Environmental crises, natural disasters, and how to invest social networks as distress and awareness tools to reduce risks are the main studies that reflected the role of social media in the strategic communication scheme. Some other studies focused on the role of social media in supporting government activities during crises, without forgetting the research that dealt with its role in fueling the Arab revolutions (the so-called Arab revolutions were launched from Facebook). There is a lack of in-depth case studies on communication crises and the uses of social media, as all studies were descriptive and general. Therefore, the author choses to delve into two cases of great importance in the fields of politics and health.

The problem is formulated as follows: What are the communications, PR and Marketing actors' perceptions regarding the uses of social media as a tool for strategic communication in times of crisis?

RQ1: How do representatives of communications, public relations, and marketing view the experiences of using social media as a strategic communication tool in times of crisis?

RQ2: What are the features of the optimal use of social media in times of crisis?

\section{METHOD}

The research comprises mixed methods; a content analysis of a sample of articles published online from 16 to 26 July 2016 was conducted in the first part. The total number of articles obtained during the data collection through the search engine

\begin{tabular}{|c|c|c|c|c|c|c|c|c|c|c|c|c|}
\hline $\begin{array}{c}\text { Publication } \\
\text { date }\end{array}$ & $\begin{array}{c}\text { The } \\
\text { reasons } \\
\text { lie only } \\
\text { in Face- } \\
\text { Time }\end{array}$ & $\%$ & $\begin{array}{c}\text { The } \\
\text { reasons } \\
\text { lie only } \\
\text { in the } \\
\text { presiden } \\
\text { t's } \\
\text { speech }\end{array}$ & $\%$ & $\begin{array}{c}\text { The } \\
\text { reasons } \\
\text { lie in } \\
\text { Face- } \\
\text { Time } \\
\text { and the } \\
\text { presiden } \\
\text { t's } \\
\text { speech }\end{array}$ & $\%$ & $\begin{array}{l}\text { The news } \\
\text { was } \\
\text { published } \\
\text { without } \\
\text { addressing } \\
\text { the causes } \\
\text { of the coup }\end{array}$ & $\%$ & $\begin{array}{c}\text { Others } \\
*\end{array}$ & $\%$ & Total & $\%$ \\
\hline $16 / 07 / 2016$ & 9 & 22.5 & 4 & 10 & 5 & 12.5 & 2 & 5 & 4 & 10 & 24 & 60 \\
\hline $17 / 07 / 2016$ & -- & -- & 2 & 5 & 1 & 2.5 & -- & -- & 2 & 5 & 5 & $\begin{array}{c}12 . \\
5\end{array}$ \\
\hline $18 / 07 / 2016$ & 1 & 2.5 & 2 & 5 & 1 & 2.5 & -- & -- & 1 & 2.5 & 5 & $\begin{array}{c}12 . \\
5\end{array}$ \\
\hline $19 / 07 / 2016$ & -- & -- & 1 & $\begin{array}{l}2 . \\
5\end{array}$ & -- & -- & 1 & 2.5 & 1 & 2.5 & 3 & 7.5 \\
\hline
\end{tabular}

"Google", by putting the keywords "causes of the failed coup +Turkey + July 2016", was 40 articles written in the Arabic language; 24 of them were published on 07/16/2016. (See detailed description in Appendix 1and 2).

During the content analysis, the author is referring to the following categories:

- The subject: A special focus is put on the articles that dealt with the reasons for the failure of the coup;

- The trend: The perceptions of the online media channels as well as research centers' publications will be analyzed;

- The type: The features of the data will be investigated;

- The format: The focus will be on photos or videos accompanying the published articles, as well as the journalistic format (s) used.

The second part includes a semi structured interviews with Arab experts working in the fields of communication, public relations, and marketing. Interviews were conducted online via Skype, Zoom and Microsoft Teams platforms, during the quarantine period due to the Covid-19 pandemic (from March 18th to April 18th, 2020). 20 participants volunteered for a 20-25 minute recorded interview sessions.

\section{RESULTS}

Part 1: Social media uses during the political crisis

The analysis of the published articles included in the sample was guided by two main questions:

- How did the online publications present the use of Face-Time by the Turkish president during the attempted coup? (Peculiarities of press coverage)

- To what extent is Face Time seen as the main reason for the failure of the attempted coup in Turkey?

Concerning the subject of communication (causes of reversal failure), the data revealed the following information included in the Table 1: 


\begin{tabular}{|l|c|c|c|c|c|c|c|c|c|c|c|c|}
\hline $21 / 07 / 2016$ & -- & -- & 1 & 2. & -- & -- & -- & -- & -- & -- & 1 & 2.5 \\
& & & & 5 & & & & & & & & \\
\hline $29 / 07 / 2016$ & -- & -- & -- & -- & -- & -- & -- & -- & 1 & 2.5 & 1 & 2.5 \\
\hline $08 / 08 / 2016$ & 1 & 2.5 & -- & -- & -- & -- & -- & -- & -- & -- & 1 & 2.5 \\
\hline
\end{tabular}

Table 1: Sample repartition according to the subject of communication.

Table 1 shows that the first noticeable reason for the failure of the Turkish coup attempt, by the sample, is the FaceTime application (27.5\%), and the Turkish president's speech content comes in second place (25\%).

It should be highlighted that during the coverage of the first day of the crisis, the focus was on the vital role of social media as an effective communication tool during the considered political crisis, but the talk about Face-Time began to diminish in the following days; the focus was on several other possible reasons to refute the coup, most notably the presidential speech on the night of the crisis.

\begin{tabular}{|c|c|c|}
\hline Online publications' types & $\mathrm{N}$ & $\%$ \\
\hline Arab TV channels' web sites & 7 & 17.5 \\
\hline Online News web sites & 17 & 42.5 \\
\hline Web sites of newspapers and News Agencies & 12 & 30 \\
\hline Web sites of Research and Studies Centers & 4 & 10 \\
\hline Total & 40 & 100 \\
\hline
\end{tabular}

Table 2: Sample repartition according to the type of communication.

According to table 2, the data includes articles published in several sources on the Internet: News websites (42.5\%), websites of newspapers and news agencies (30\%), websites of Arab TV channels (17.5\%), and the websites of research centers $(10 \%)$.
It has to be pointed out that the diversity found in the types of publications included in the sample indicates a discoloration in their formats: while News web sites focus on real-time short news formats and immediate coverage, Research Centers issue careful, in-depth, studied and lengthy publications.

\begin{tabular}{|c|c|c|c|c|c|c|c|c|c|c|c|c|}
\hline $\begin{array}{l}\text { Publication } \\
\text { date }\end{array}$ & $\begin{array}{l}\text { Turkey's } \\
\text { president } \\
\text { via Face- } \\
\text { Time }\end{array}$ & $\%$ & $\begin{array}{l}\text { People } \\
\text { are } \\
\text { above } \\
\text { tanks }\end{array}$ & $\%$ & $\begin{array}{l}\text { Turkey } \\
\text { Flag }\end{array}$ & $\%$ & $\begin{array}{l}\text { No } \\
\text { photos }\end{array}$ & $\%$ & $\begin{array}{l}\text { Others } \\
*\end{array}$ & $\%$ & Total & $\%$ \\
\hline $2016 / 07 / 16$ & 21 & 52.5 & -- & -- & -- & -- & 2 & 5 & 1 & 2.5 & 24 & 60 \\
\hline $2016 / 07 / 17$ & 2 & 5 & -- & -- & 2 & 5 & 1 & 2.5 & -- & -- & 5 & 12.5 \\
\hline $2016 / 07 / 18$ & 1 & 2.5 & 2 & 5 & -- & -- & 2 & 5 & -- & -- & 5 & 12.5 \\
\hline $2016 / 07 / 19$ & -- & & 1 & 2.5 & -- & -- & 2 & 5 & -- & -- & 3 & 7.5 \\
\hline $2016 / 07 / 21$ & 1 & 2.5 & -- & -- & -- & -- & -- & -- & -- & -- & 1 & 2.5 \\
\hline $2016 / 07 / 27$ & -- & & -- & -- & -- & -- & 1 & 2.5 & -- & -- & 1 & 2.5 \\
\hline $2016 / 08 / 08$ & 1 & 2.5 & -- & -- & -- & -- & -- & -- & -- & -- & 1 & 2.5 \\
\hline Total & 26 & 65 & 3 & 7.5 & 2 & 5 & 8 & 20 & 1 & 2.5 & 40 & 100 \\
\hline
\end{tabular}

Table 3: Repartition of the sample according to the content of the published photos. 
According to Table 3, 65\% of the sample articles comprise a photo of the Turkish president via Face-Time, of which $52 \%$ were published immediately after the coup failed (7/16/2016). Besides, the sample does not include video clips accompanying the published articles.

It should be noted that a large percentage $(20 \%)$ of the articles were published without pictures. This can be explained by the presence of a specific type of in-depth analytical articles that have been published on the sites of the Research Centers; this type of articles does not necessarily need pictures or videos because the elements of support are present through the problematic approach addressed. Unlike electronic articles or web-based journalism that rely on images, videos, and links along with a short text, research articles rely on in-depth analytical ideas that call for an argumentative problematic pattern.

\section{Part2: Covid-19 pandemic and social media use}

In this part, the main question regarding trends around social media as a powerful strategic communication tool in times of crisis remains on the table, but will be covered with a different approach; the focus will be on another crisis: A global health crisis the world is still suffering from, the Coronavirus pandemic.

A number of 20 experts in the fields of Communications, PR and Marketing volunteered for a 20-25 minute interview session. The interview guide consists of three main questions as follows:

1. Do you use social media during the quarantine period and for what purpose?

2. Tell me about your professional experience using social media to manage crises in your workplace?

3. According to you, what is your definition of social media effective use in times of crisis such as the Coronavirus pandemic?

The findings of the interviews describing the participants' perceptions and behaviors regarding the use of social media during the quarantine period are presented as follows:

1. Do you use social media during the quarantine period and for what purpose?

With regard to the first question, there is consensus on the purposes of using social media, which are summarized into two needs:

- Personal needs;

- Professional needs.

As for the personal needs, social media is perceived as an excellent source for providing news about the pandemic (See the Table 4).

\begin{tabular}{|c|}
\hline News followed during the quarantine period \\
\hline Number of infections and deaths \\
\hline The economic implications \\
\hline Risks of Coronavirus to human health \\
\hline Possible medical treatments \\
\hline Quarantine instructions \\
\hline WHO announcements and statements \\
\hline Penalties for breaking quarantine \\
\hline
\end{tabular}

Table 4: Kind of news followed via social media during the quarantine period.

Included among the personal needs also, the desire to communicate with distant family members and friends. One participant explained "Being away from extended family and relatives may affect a person's psyche and lead to illness. Social isolation is one of the causes of health problems, especially depression. That's why, I consider social media a lifeline for me and my family; linking bridges of communication and erasing boundaries, via video chatting make the sense of isolation less".

The third personal need is related to supply daily essentials from the market such as food, drinking, clothing and electronics; one participant noted a huge increase regarding online shopping in the absence of open stores.

As for the professional needs, participants summarized them in the remote running of work; the participants explained that the quarantine period represented an opportunity to increase their efficiency in a number of platforms and applications of modern technologies to ensure work continuity. "With the outbreak of this crisis, social media can be a great tool not only for personal communication, but also for business by investing in the technical capabilities available to communicate with customers, make deals and attract audiences, especially since the percentage of users is at its peak in such circumstances", a public relations manager explicated.

A marketing professional added: "Remote work almost does not cost anything but time, and social media has an essential role in securing the continuity of communication with colleagues and clients. It also leads, if invested well, to linking larger and closer relationships, because it is an informal means and thus can be used for covert marketing purposes in greeting messages and compliments, for example".

2. Tell me about your professional experience using social media to manage crises in your workplace? 
The aim of the second question is to verify the participants' behaviors regarding the use of social media during the quarantine period. The data showed that in addition to its role in supporting the communication process, social media is credited with improving and developing professional relations within the work environment. A communications expert expressed his great satisfaction while using social media to communicate with his peers: "Under exceptional circumstances, we can do extraordinary things. Informal communication through social media, even in professional matters, can help reduce peer animosity in the workplace. It also provides a good channel to help each other. My relationship with my colleagues has gotten better and better since we switched to working online".

In the same context, a number of participants indicated that the quality of customer services during the quarantine period and the transition to remote work did not decrease. A manager in a private Marketing company declared: "Communication with clients during crises is vital; social media is a miracle in this regard. I have had the opportunity to communicate about many transactions and complaints using social media for discussion and negotiation, and I have already reached many agreements and solved a large number of problems through chatting over social media platforms with stakeholders."

It should be noted that some participants showed caution and reservations about trusting the role of social media in managing the communication process in times of crisis, stressing that these networks are, in fact, a double-edged sword. An expert of public relations enlightened his fears: "It's great that companies can incorporate social media as part of their crisis PR strategy, but it is incredibly powerful and can turn a bad situation into a real opportunity to demonstrate goodwill; I am speaking based on my personal experience of this matter; I had a misunderstanding with clients who posted negative comments about me and found myself trapped in an extra crisis". Another added that social media is a hotbed of rumors and false news, which limits its effectiveness as a tool for strategic communication; especially in critical times such as crises; "The reputation of the organization takes years to build, and social media can destroy it in an instant through a tweet or an unintentional mistake in a post. This, in turn, takes months to regain it and restore people's confidence", he clarified.

Thus, a number of participants linked the main feature of social media as a source of news dissemination, to the high risk of distortion that could occur.

3. According to you, what is your definition of effective use of social media in times of crisis?

The answers to the typical use of social media in times of crisis included an emphasis on the need to be diplomatic while dealing with customers and accepting their criticisms with a cold blooded temper. The participants emphasized that it is important not to forget that the opposite party suffers from a state of turmoil and lack of information and in worse cases, of panic and fear; so, it is necessary to use the available resources (social media) to maintain a good understanding with clients; the customer must constantly be informed and aware of what is happening. A public relations manager explained: "Social media is a public platform, and our followers have the right to post negative comments. It is important that you know how to turn these negative comments and defend yourself to change them from a negative to a positive attitude."

In the same context, one of the participants added that: "Satisfying our customers online is vital especially in times of crisis, responding to their tweets, mentions, and comments on company profiles in a timely manner. Social media works in real time, so the faster you respond, the better your customer service will look."

A number of participants focused on the strength of social media as a tool for strategic communication in emergency situations, stressing the need to practice the basics of an effective communications plan within the organization and in the workplace in general, considering that cutting communication channels during crises is a real danger that must be avoided. "Strategic communication is the key word for crisis management, and when you fail to reach customers through official channels, social media can be a better server for them; allow customers to contact you informally via social networks, discuss their inquiries with them, answer their questions and try to reduce their anxiety." One participant elucidated.

Nevertheless, some of the participants are better to warn of the slippages that specialists in the field of communication and public relations may fall into and how to escape from them. "Social networks can be an essential communication tool for effective crisis management but they can make a crisis worse if not used strategically", as one participant expounded, adding that "the nature of social media requires it to be approached with caution. Only a strategic approach to crisis management through social media will enable you to harness its potential while ensuring that it works for you, not against you".

\section{DISCUSSIONS}

Regarding the first case study related to the Turkish political crisis, Face-Time is perceived as the main reason for the failure of the military coup in Turkey on the night of 15 July 2016, according to the majority of sample articles published online, especially on the first day. In the following days, the focus was placed on several other possible causes, chief among them the presidential speech on the night of the crisis. Consequently, the peculiarities of online press coverage and how online publications dealt with the use of Face-Time as a communication tool to manage the Turkish crisis, it must be emphasized that there has been a large wave of articles that reflected surprise and amazement with regards to the mentioned use. The Turkish President's use of the social media application despite his declared negative stance on the issue of the use of social networks in the past reflects the central role that Face-Time played as the only outlet for him to 
communicate with the TV channel anchor who acted as a mediator between him and the target audience in those critical times.

Meanwhile, regarding trends about the role of social media in managing communication operations during the political crisis, the researcher concludes that there is an overwhelming trend that supports the use of Face-Time in this matter, but there is no consensus on this position. There is a minority that has tendency to marginalize social networks impact and considers Face-Time merely a link that served as a medium for communication with a journalist of CNN Turk, as the TV interview was broadcast live. Thus, Television remains the main tool for influencing the communication process.

Despite this point of view, it has to be underlined that the use of social media in political campaigns and propaganda is witnessing a steady development, as is the case in the United States of America, where the president frequently uses Twitter to address his people, trying to influence them and express his views on public opinion issues.

Thus, the focus in the first part of this research was on the trends of digital / online communication actors' publications (Journalists, communicators, researchers...etc.), towards social media as a strategic communication tool during the political crises. Findings revealed that the predominant trend is to value social media for political crisis communication management operations; this could be explained by the opportunities offered by the virtual space, especially the speed and the infinite breadth of recipients which facilitate the information circulation.

As per the second case study on the perception and behavior of communication, public relations and marketing experts regarding social media during the quarantine period, findings of the conducted interviews revealed that the purposes of using social media are guided by personal and professional needs. Like anyone in the world suffering from the isolation due to the quarantine measurements, participants used social media to keep being informed about crisis news, maintain personal relationships with family and friends, and to shop online. In the same context, Horth et al. [21] confirmed the role of social media in managing distress and grief, while addressing Japan earthquake and the tsunami of March 11, 2011.

Therefore, social media is seen as rescue plan for people in times of crisis; Saroi and Pal inveterate the efficient role of social media news in creating and spreading awareness messages; they also noted that social media could play in helping governments manage emergencies and minimize harms.

As per interviewees' professional needs, participants fled to remote work to keep their work; they clarified that the quarantine period represented an opportunity for them to increase their efficiency in a number of modern technology platforms and applications, including social media, to ensure business continuity. Regarding their behaviors regarding the use of social media, the interviewees acknowledged that the aforementioned networks support them in their interactions with superiors, peers and clients; In the meantime, an improvement in their professional relationships was observed within the work environment as online chatting developed a friendly atmosphere that enhanced the quality of customer services during the quarantine period and the transition to remote work. They had the opportunity to communicate about numerous transactions and complaints; they also came to many agreements and solved a large number of issues by chatting on social media platforms with stakeholders.

In fact, the eminent role played by social media to help the communication experts, interviewed in this study, meets with what GWU and Cision [20] revealed in their research, about the increasing use of social media by journalists to generate news.

However, a number of participants stated their bad experience of interacting with customers through social media (misunderstanding with clients, negative posts, comments, etc.). Thus, they expressed caution and reservations about confidence in the role of social media in managing the communication process in times of crisis, stressing that these networks are in fact a double-edged sword. This statement meets with what was concluded by Lee et al. [18] about the complexity of the relationship between social media users and organizations.

Finally, to answer the first research question about how do representatives of communications, public relations, and marketing view the experiences of using social media as a strategic communication tool in times of crisis, it has to be emphasized first that an overwhelming tendency to support the action of using Face-Time application by the Turkish president during the political crisis of 2016; nevertheless, a minority of studied publications seemed to marginalize social media impact considering that Face-Time served merely as a medium for communication to link the journalist of CNN Turk to the president Ardoghan, as the TV interview was broadcast live. Hence, Television is still seen as the main tool that influenced people by minority of published online articles. Second, social media seemed to be a great saver for organizations in times of crisis according to interviewed communicators, PR and Marketing experts; they clarified that the communication with customers during the times of crises is vital, and social media is seen as a miracle in this regard; in the interim, some participants showed caution and reservations about trusting social media use in times of crisis, stressing that these networks are a double-edged sword.

As per the second research question concerning the features of the optimal use of social media in times of crisis, participants insisted on the need to maintain a high level of understanding and diplomacy while dealing with clients, accept their criticisms and keep them informed and aware of what is happening. Interviewees insisted that a strategic communications plan is the key word for crisis management. 


\section{Business and Management Research (IJBMR)} Research Article | Volume 8, Issue 3 | Pages 64-72 | e-ISSN: 2347-4696

Informal communication via social media should take place to discuss with clients their inquiries, answer their questions and try to reduce their anxiety. Some participants emphasized that social media is able to be an essential communication tool for effective crisis management but can make a crisis worse if not used strategically; a strategic approach to crisis management through social media is perceived worth to enable Communicators, PR and Marketing agents to harness the potential of networks.

\section{CONCLUSION}

It is to highlight at the end of this research article, that nowadays crisis management inevitably includes social media; when a crisis occurs; social media should therefore be the first place to reach by communicators and crisis managers. It was previously mentioned that the characteristics of social media make it an ideal tool for communicating quickly and effectively. Communication on social media is prompt, transmitting messages instantly (in contrast to media materials published in traditional mass communication means). It must also be taken into account the quasi-total availability of the audience on the Internet, as most customers are followers on social media; these platforms give organizations an opportunity to transmit messages directly to targeted people and communicate with them online. Hence, the best communicators are those who take a position to direct the conversation online during and after a crisis; to help steer the dialogue in a more positive and productive way.

The research supported the trend that appreciates the escalating role of social media networks in the field of crises in all its branches, and also showed the impact that it can have in changing the course of political events in critical times, as well as its weight as a savior in the absence of face-to-face communication during health crises and the need to diverge between Humans. Faced with the imperative to resort to social media in difficult times, it is imperative that future research focus on the fundamentals and mechanisms of optimal use and how to overcome potential pitfalls when using it.

\section{REFERENCES}

[1] Paul, T. J., Shneiderman, B., Kenneth, R. F., Jennifer, P., Yan, Q., Philip Fei W. (2007), Community response grids: E-government, social networks, and effective emergency management, Telecommun. Pol. 31 (10) 592-604.

[2] Havlik, D., Pielorz, J. Adam, W. (2016), Interaction with Citizens Experiments: from Context-Aware Alerting to Crowd tasking, ISCRAM, 2016.

[3] Plotn, L., Hiltz, R. S., Kushma, J. A., Andrea, H., Tapia, R. T. (2015), Attitudes and Issues Related to Use of Social Media by Us County-Level Emergency Managers, ISCRAM.

[4] Vieweg, S., Hughes, A.L., Starbird, K., Palen, L. (2010), Microblogging during two natural hazards events: what twitter may contribute to situational awareness, in: Proceedings of the SIGCHI Conference on Human Factors in Computing Systems, ACM, 2010, pp. 1079-1088.
[5] Marcelo, M., Barbara P., Carlos, C. (2010), Twitter under crisis: Can we trust what we rt?, in: Proceedings of the First Workshop on Social Media Analytics ACM, pp. 71-79.

[6] Snoussi, T., Saeed, M., \& Qandil H. (2019), Crisis and Terrorism Communication, Bright Horizons Publishers, First Edition, United Arab Emirates, 336 pages.

[7] Heath, R. L. and Palenchar, M. J. (2009). Strategic issues management: Organizations and public policy changes, 2nd ed, Thousand Oaks, CA: Sage.

[8] Reynolds, B., Seeger, M.W. (2005). Crisis and emergency risk communication as an integrative model. Journal of Health Communication Research, 10(1): 43-55.

[9] Seeger, M. W. (2006). Best practices in crisis communication: An expert panel process. Journal of Applied Communication Research, 34(3): 232 244.

[10] Kaplan, A. M., \& Haenlein, M. (2010). Users of the world, unite! The challenges and opportunities of social media. Business Horizons, 53(1), $59-68$.

[11] Coombs, W. T. (2008). Crisis communication and social media Essential Knowledge Project, Institute for Public Relations.

[12] Snoussi, T., et al. (2016), The media as a making crisis partner, Journal of the Middle East Public Relations Research, Egyptian Public Relations Association, Issue 13, fourth year, October-December.

[13] Kumar, V., \& Nanda, P. (2019). Social media in higher education. International Journal of Information and Communication Technology Education, 15(1), 97-108.

[14] Jessica, G., L. Nikki, and B. Mara. (2018. "Social media in the mentorship and networking of physicians: Important role for women in surgical specialties.” Am. J. Surg. 215 (4): 752-760.

[15] Parusheva, S., Alexandrova, Y., \& Hadzhikolev, A. (2018). Use of Social Media in Higher Education Institutions - an Empirical Study Based on Bulgarian Learning Experience. TEM Journal, 171-181.

[16] Al Jenaibi, B. (2015). Use of Social media in the UAE. Journal of Media Critiques, 1(1), 48-60.

[17] Bernadetha Nadeak (2020). The Effectiveness of Distance Learning Using Social Media during the Pandemic Period of COVID-19: A Case in Universitas Kristen Indonesia, International Journal of Advanced Science and Technology. Vol. 29, No. 7, (2020), pp. 1764-1772.

[18] Lee, I. (2018). Social media analytics for enterprises: Typology, methods, and processes. Business Horizons, 61(2), 199-210.

[19] Luc, J. G., Stamp, N. L., \& Antonoff, M. B. (2018). Social media in the mentorship and networking of physicians: Important role for women in surgical specialties. The American Journal of Surgery, 215(4), 752-760.

[20] GWU \& Cision. (2009). Social media \& online usage study.

[21] Larissa, H. Kyoung, H., Yonnie, K., Good, G. (2011), the role of social mobile media in the 3.11 earthquake disaster in Japan, Digit. Creativ. 22 (3) $187-199$

[22] Subba, R., Tung, B. (2017), online convergence behavior, social media communications and crisis response: an empirical study of the 2015 Nepal earthquake police twitter project, in: Proceedings of the 50th Hawaii International Conference on System Sciences, 2017.

[23] Power, R., Kibell, J. (2017), the social media intelligence analyst for emergency management, in: Proceedings of the 50th Hawaii International Conference on System Sciences. 


\section{APPENDICES}

\begin{tabular}{|c|c|c|}
\hline No. & Publication date & Links of the sample articles \\
\hline 1 & $2016 / 7 / 16$ & https://arabic.rt.com \\
\hline 2 & $2016 / 07 / 16$ & http://www.kurdistan24.net \\
\hline 3 & $2016 / 07 / 16$ & https://arabi21.com \\
\hline 4 & $2016 / 07 / 16$ & http://www.france24.com \\
\hline 5 & $2016 / 07 / 16$ & https://biicon.net \\
\hline 6 & $2016 / 07 / 16$ & www.worldakhbar.com \\
\hline 7 & $2016 / 07 / 16$ & www.3alyoum \\
\hline 8 & $2016 / 07 / 16$ & http://akhbar24.argaam.com \\
\hline 9 & $2016 / 07 / 16$ & www.nrttv.com/ar \\
\hline 10 & $2016 / 07 / 16$ & https://www.nmisr.com \\
\hline 11 & $2016 / 07 / 16$ & www.tehamapress.com \\
\hline 12 & $2016 / 07 / 16$ & http://arabic.cnn.com \\
\hline 13 & $2016 / 07 / 16$ & www.akhbaralaan.net \\
\hline 14 & $2016 / 07 / 16$ & http://arabhardware.net \\
\hline 15 & $2016 / 07 / 16$ & www.noonpresse.com \\
\hline 16 & $2016 / 07 / 16$ & http://shabab.ahram.org.eg \\
\hline 17 & $2016 / 07 / 16$ & www.bbc.com \\
\hline 18 & $2016 / 07 / 16$ & http://solve2problem.com \\
\hline 19 & $2016 / 07 / 16$ & www.raialyoum.com \\
\hline 20 & $2016 / 07 / 16$ & www.masralarabia.com \\
\hline 21 & $2016 / 07 / 16$ & www.annahar.com \\
\hline 22 & $2016 / 07 / 16$ & www.accronline.com \\
\hline 23 & $2016 / 07 / 16$ & akhbarelyoum.com \\
\hline 24 & $2016 / 07 / 16$ & www.emaratalyoum.com \\
\hline
\end{tabular}

Appendix 1: Links of the coverage immediately after failure of the coup attempt.

\begin{tabular}{|c|c|c|}
\hline No. & Publication date & Links of the sample' articles \\
\hline 1 & $2016 / 07 / 17$ & www.albawaba.com/ar \\
\hline 2 & $2016 / 07 / 17$ & www.skynewsarabia.com \\
\hline 3 & $2016 / 07 / 17$ & http://arab-mirror.com \\
\hline 4 & $2016 / 07 / 17$ & http://altagreer.com \\
\hline 5 & $2016 / 07 / 17$ & http://alwafd.org \\
\hline 6 & $2016 / 07 / 18$ & www.aawsat.com \\
\hline 7 & $2016 / 07 / 18$ & www.noonpost.net \\
\hline 8 & $2016 / 07 / 18$ & www.kitabat.info \\
\hline 9 & $2016 / 07 / 18$ & http://annabaa.org \\
\hline 10 & $2016 / 07 / 18$ & www.palinfo.com \\
\hline 11 & $2016 / 07 / 19$ & www.alittihad.ae \\
\hline 12 & $2016 / 07 / 19$ & www.asharqalarabi.org.uk \\
\hline 13 & $2016 / 07 / 19$ & http://mourassiloun.com \\
\hline 14 & $2016 / 07 / 21$ & www.alaraby.co.uk \\
\hline 15 & $2016 / 07 / 27$ & http://rawabetcenter.com \\
\hline 16 & $08 / 08 / 2016$ & www.turkpress.co \\
\hline
\end{tabular}

Appendix 2: Links of coverage in the days / weeks following the attempted coup in Turkey.

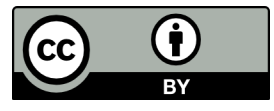

(C) 2020 by the Thouraya Snoussi. Submitted for possible open access publication under the terms and conditions of the Creative
Commons Attribution (CC BY) license

(http://creativecommons.org/licenses/by/4.0/). 